\title{
SENTIDO DO CUIDADO EM SAÚDE MENTAL: SOBRE A REDE DE ATENÇÃO PSICOSSOCIAL DO SISTEMA ÚNICO DE SAÚDE (SUS)
}

\author{
MEANING FOR MENTAL HEALTH CARE: ABOUT THE PSYCHOSOCIAL \\ CARE NETWORK OF UNIFIED HEALTH SYSTEM
}

SENTIDO DEL CUIDADO EN SALUD MENTAL: SOBRE LA RED DE

ATENCIÓN PSICOSOCIAL DEL SISTEMA UNICO DE SALUD

\author{
Ariélly Cristina Fidelis ${ }^{1}$
}

Resumo Diferentes concepções de cuidado permeiam o setor da saúde e influenciam as práticas adotadas em todos os campos, inclusive o da saúde mental. Nesta pesquisa buscou-se sentido para o cuidado em saúde mental na Rede de Atenção Psicossocial do Sistema Único de Saúde do Brasil. O estudo configura-se metodologicamente como qualitativo de cunho fenomenológico, com base no referencial hermenêutico de Heidegger. O caminho analítico foi inspirado também pela Antropologia Visual e o seu fazer etnográfico. O esforço empreendido ocorreu com a seleção de 21 fotografias que retratam vivências que apontam para o cuidado exercido no interior dos dispositivos de saúde mental. Por meio destas imagens, o sentido do cuidado exercido nos dispositivos da Rede de Atenção Psicossocial emergiu ainda atrelado à noção de cuidado baseado em ações efetivas e ao funcionamento considerado adequado exclusivamente por meio de cumprimento de protocolos, critérios e atividades assistenciais preconizadas nos manuais. $\mathrm{O}$ cuidado considerado necessário para o âmbito da saúde mental é o que valoriza as pessoas, interessa-se por seus sentimentos e mantém expectativas quanto ao que os profissionais possam vir a colaborar para a satisfação das suas necessidades, para a redução do seu sofrimento e para a reconfiguração dos dispositivos de saúde.

Palavras-chave saúde mental; cuidado centrado no paciente; Sistema Único de Saúde; etnografia; fotografia.
Abstract Different conceptions of care permeate the health sector playing an important role in the practices adopted in all fields, including mental health. This research sought meaning for mental health care in the Psychosocial Care Network of Brazilian Unified Health System. The study is methodologically of a phenomenological qualitative nature, from the heideggerian hermeneutics referential. The analytical path was also inspired by the reference of Visual Anthropology and its ethnographic approach. The efforts undertaken in this research came up from the selection of 21 photographs that depict different experiences about the care exercised inside some devices of mental health. From these images, the meaning of care exercised in the Psychosocial Care Network devices emerged as still linked to the notion of care based on effective actions and operations considered appropriate only by following protocols, welfare criteria and activities recommended on manuals. The care deemed necessary for the scope of mental health is one that values people, is interested in their feelings and expectations as to what professionals can come to collaborate to meet the needs, reduce people's suffering and to the reconfiguration of health devices.

Keywords mental health; patient-centered care; unified health system; ethnography; photography. 


\section{Introdução}

O advento da Reforma Psiquiátrica no Brasil, nos anos 1980, se deu por meio de reivindicações pautadas em mudanças nos modelos de atenção e de gestão das práticas psiquiátricas no país, o que gerou um processo político e social complexo (Brasil, 2005). Sabe-se que o processo brasileiro sofreu influências de diferentes propostas de reformas no setor psiquiátrico ocorridas no século XX em várias partes do mundo. Estas reformas buscaram romper com o modelo clássico da psiquiatria desenvolvido por Pinel, que mantinha o foco na doença e centralizava as intervenções no âmbito hospitalar, que culminou na institucionalização da loucura. As inovações apresentadas por estes modelos reformistas ligam a assistência a pessoas em sofrimento psíquico ao coletivo e ampliam as intervenções para o âmbito familiar e comunitário (Amarante, 1995; Schechtman e Alves, 2014).

Ao atender, em parte, às reinvindicações da Reforma Psiquiátrica no Brasil, expressas no projeto de lei n. 3.657/89, o sistema de saúde brasileiro estabeleceu a Política Nacional de Saúde Mental, baseada na lei n. 10.216/2001. Nesta política, são apresentadas diretrizes para a condução da assistência em saúde mental no país, onde se pressupõe que as referências de isolamento e os tratamentos invasivos sejam substituídos por tratamentos que zelem pela reinserção social, participação da família e da comunidade e, também, pelo respeito à pessoa assistida (Souza, 2011). A política sugere uma assistência prioritariamente voltada para dispositivos comunitários, em que apenas em caso extremo a internação em hospitais psiquiátricos deve ser solicitada.

Dez anos depois da referida lei, em 2011, por meio da portaria n. 3.088/11, foi instituída, no âmbito do Sistema Único de Saúde (SUS), uma rede específica para saúde mental de base comunitária: a Rede de Atenção Psicossocial (RAPS), que tem por objetivo estabelecer dispositivos assistenciais para pessoas em sofrimento psíquico e para aqueles que possuem necessidades de assistência de saúde em decorrência do uso de crack, álcool e outras drogas. A RAPS é uma proposta de substituição do modelo asilar. Esta rede foi estruturada com sete eixos de atuação, aos quais estão vinculados diferentes dispositivos e serviços específicos (Quadro 1).

Entre todos os dispositivos pertencentes à RAPS, o Ministério da Saúde considera o Centro de Atenção Psicossocial (CAPS) como o principal articulador entre os demais serviços e estratégico na organização da rede de atenção em saúde mental. Os CAPS devem permanecer articulados com a rede de atenção à saúde e com as demais redes sociais que os circundam, de modo a responderem à demanda de assistência no espaço comunitário e de reinserção social (Brasil, 2004). 


\begin{tabular}{|c|c|c|c|c|c|c|}
\hline \multicolumn{7}{|c|}{ Demonstração da Rede de Atenção Psicossocial do SUS } \\
\hline \multicolumn{7}{|c|}{ Rede de atenção psicossocial } \\
\hline $\begin{array}{l}\text { Atenção } \\
\text { básica em } \\
\text { saúde }\end{array}$ & $\begin{array}{l}\text { Atenção } \\
\text { psicossocial } \\
\text { especializada }\end{array}$ & $\begin{array}{l}\text { Atenção de } \\
\text { urgência e } \\
\text { emergência }\end{array}$ & $\begin{array}{l}\text { Atenção } \\
\text { residencial } \\
\text { de caráter } \\
\text { transitório }\end{array}$ & $\begin{array}{l}\text { Atenção } \\
\text { hospitalar }\end{array}$ & $\begin{array}{l}\text { Estratégias de } \\
\text { desinstitucionalização }\end{array}$ & $\begin{array}{l}\text { Reabilitação } \\
\text { psicossocial }\end{array}$ \\
\hline $\begin{array}{l}\text { Unidade } \\
\text { básica de } \\
\text { saúde }\end{array}$ & $\begin{array}{l}\text { Centro de } \\
\text { atenção } \\
\text { psicossocial }\end{array}$ & Samu & $\begin{array}{l}\text { Unidade de } \\
\text { acolhimento }\end{array}$ & $\begin{array}{l}\text { Enfermaria } \\
\text { especializada } \\
\text { em } \\
\text { hospitais } \\
\text { gerais }\end{array}$ & $\begin{array}{l}\text { Programa de } \\
\text { residências } \\
\text { terapêuticas }\end{array}$ & $\begin{array}{l}\text { Iniciativas de } \\
\text { geração de } \\
\text { trabalho e } \\
\text { renda }\end{array}$ \\
\hline $\begin{array}{l}\text { Consultório } \\
\text { de rua }\end{array}$ & & $\begin{array}{l}\text { Sala de } \\
\text { estabilização }\end{array}$ & $\begin{array}{l}\text { Serviços } \\
\text { de atenção } \\
\text { em regime } \\
\text { residencial }\end{array}$ & $\begin{array}{l}\text { Serviço } \\
\text { hospitalar } \\
\text { de } \\
\text { referência }\end{array}$ & $\begin{array}{l}\text { Programa De Volta } \\
\text { pra Casa }\end{array}$ & $\begin{array}{l}\text { Empreendimentos } \\
\text { solidários }\end{array}$ \\
\hline $\begin{array}{l}\text { Apoio aos } \\
\text { serviços } \\
\text { residenciais } \\
\text { de caráter } \\
\text { transitório } \\
\text { Centro de } \\
\text { convivência }\end{array}$ & & UPA $24 \mathrm{~h}$ & & & & $\begin{array}{l}\text { Cooperativas } \\
\text { sociais }\end{array}$ \\
\hline
\end{tabular}

Fonte: A autora.

De acordo com Guljor (2003), o paradigma da atenção psicossocial possui características essenciais que diferem do modelo asilar e propõe (re)orientar as ações em saúde mental. Na atenção psicossocial, a pessoa que sofre é vista por meio da sua história de vida, de seus desejos. Ela deixa de ser reduzida à doença, como acontece no modelo hegemônico, e passa a ser considerada em sua totalidade, nas várias dimensões de sua existência. Deste modo, ressalta a autora, deixa-se de focar as intervenções na extinção dos sintomas e passa-se a valorizar e problematizar aspectos da vida cotidiana da pessoa. A atenção psicossocial ultrapassa as questões do campo da saúde e alcança as dimensões sociais.

Outro fator diferenciador da atenção psicossocial, quando comparada com o modelo hospitalocêntrico, é a forma como são desenvolvidas as ações, no que tange às técnicas empregadas. A ênfase passa a ser as atividades coletivas, as interações em grupos, as oficinas terapêuticas, que possibilitam trocas entre as pessoas, de modo a capacitá-las para outras relações fora do dispositivo, em outros meios de convívio (Guljor, 2003). 
As características essenciais da concepção de atenção psicossocial permitem constatar que apenas a implantação de dispositivos assistenciais no campo da saúde mental não é suficiente para atestar mudanças na forma de conceber a loucura e assistir a pessoa em sofrimento psíquico. A atenção psicossocial em sua essência extrapola a mera substituição de um lócus de tratamento para outro, implica mudanças teórico-conceituais, além de mudanças práticas. No momento atual - anos após o advento da Reforma Psiquiátrica Brasileira e com a instituição de uma rede de dispositivos que propõe uma atenção psicossocial ao campo da saúde mental - se torna importante olhar para os dispositivos da rede e atentar para as concepções de cuidado que têm permeado as práticas e as ações desenvolvidas nesses espaços.

As concepções de cuidado em saúde estão fortemente atreladas à ideia de efetividade e eficiência das ações, que advém de um entendimento construído ao longo dos anos, de acordo com Martins (2014). Deste modo, configurouse a noção de cuidado em saúde como um conjunto de ações cientificamente validadas, que resultam da associação entre tecnologias e saberes específicos que funcionam de forma eficiente, efetiva, eficaz, segura etc. Dito de outro modo, o cuidado em saúde é restritamente entendido como a operacionalização de ações direcionadas e programadas para uma intervenção específica dentro de uma situação em saúde.

O âmbito da saúde mental não está alheio às influências destes tipos de concepções de cuidado. Neste contexto, estas concepções apresentam-se limitadas e, até mesmo, contrastantes com os pressupostos da atenção psicossocial.

As noções de cuidado em saúde remetem a um problema a ser resolvido, o que quer dizer que a cura ou ao menos o manejo satisfatório dos sintomas é esperado. No campo da saúde mental esta expectativa também aparece. Leal e Muñoz (2014, p. 75), ao atestarem ser possível a vida em sociedade para pessoas em sofrimento psíquico, afirmam que esta possibilidade é garantida pela utilização de formas de "tratamento" que permitem às pessoas com "transtornos mentais" lidarem com os sintomas e cuidarem da "doença" no ambiente fora do contexto hospitalar.

Por meio dos aspectos levantados, é possível identificar um enfoque no manejo dos sintomas, de acordo com o diagnóstico a ser considerado pelos profissionais. O tratamento, que pode ser entendido de modo restrito como administração de medicamentos e acompanhamento sistemático do profissional da psiquiatria, é destacado como mecanismo que possibilita que pessoas em sofrimento psíquico convivam em sociedade. Assim, parece se configurar a efetividade e a eficiência no cuidado em saúde mental: no controle dos sintomas. As características apresentadas pela pessoa em sofrimento psíquico costumam ser enquadradas em um sistema de classificação dos transtornos mentais, que é utilizado para 
orientar e conduzir a construção do projeto terapêutico de acordo com o diagnóstico identificado.

O cuidado em saúde mental ainda está voltado para a resolutividade e necessita de avanços quanto à instauração da desinstitucionalização como desconstrução de paradigmas trazidos historicamente pela psiquiatria. E, também, encontra-se atrelado à noção de qualidade assistencial direcionada à operacionalização de ações e procedimentos que corroboram para a manutenção do paradigma problema-solução (Rotelli et al. 1990) que circunda a Rede de Atenção Psicossocial.

\section{Cuidado como condição originária do Ser}

Após mencionar algumas das concepções inerentes à ideia de cuidado em saúde e o modo como se manifestam nas práticas assistenciais, pretende-se apresentar a compreensão de cuidado que se acredita ser a via condutora das transformações que tanto se busca quanto à forma de direcionar as práticas de saúde no SUS e em qualquer outro espaço assistencial. Este outro modo de compreender o cuidado é apresentado na obra Ser e Tempo, do filósofo Martin Heidegger (2005).

Em Ser e Tempo, Heidegger passa a dedicar-se à ontologia fundamental do ser, ou seja, à compreensão acerca do modo de ser do homem como existência. O sentido do ser e sua verdade são colocados como problema filosófico fundamental (Heidegger, 1989; Sá e Barreto, 2011; Silva, 2012).

O filósofo buscou apresentar uma revisão de instâncias fundamentais da ontologia de Aristóteles, Descartes e Kant - o que revela a dimensão exploratória da obra quanto à questão primordial do conhecimento humano. A vertente hermenêutica da analítica existencial de Heidegger, como sua concepção de filosofia, revela um olhar voltado para questões como o mundo da vida e a historicidade, que viriam a ser pontos centrais para a crítica da teoria tradicional. O novo enquadramento hermenêutico tornava a relação sujeito-objeto, modelo das filosofias da consciência, alvo de revisão e de nova formulação (Stein, 1990).

Nesta busca pela ontologia fundamental do ser, Heidegger se atém à natureza e ao núcleo do ser humano em seu estado elementar, o qual - conclui o filósofo - é constituído por Cuidado. O vocábulo Dasein refere-se à essência do homem, seu estado primeiro, originário. O Dasein expressa que o ser não é algo solto no mundo, mas um ser-no-mundo, que conduz pelo cuidado a sua própria existência (Heidegger, 2005).

O cuidado é entendido, segundo a obra de Heidegger (2005), como o ser do Dasein, no qual está baseado ontologicamente todo o momento estrutural em seu poder-ser, é o principal ente de sua analítica existencial. 
Para apresentar seu caráter fundamental, Heidegger (2005) pontua que o entendimento do cuidado está para além de uma compreensão ontológica, ou mesmo, para o conhecimento ôntico dos entes. O filósofo ressalta que para a interpretação existencial do Dasein como cuidado é preciso confirmar sua condição pré-ontológica. Para isto, a analítica existencial, que acessa o fenômeno do Cuidado, deve estar direcionada para a problemática ontológica fundamental: a questão acerca do sentido do ser. Deve, também, reexaminar de forma ainda mais profunda os fenômenos atrelados ao ser.

Por meio destas unidades fundamentais, o Cuidado pode ser entendido como o ser do Dasein, como estrutura fundante que existe existencialmente antes de qualquer cuidar ôntico, seja por objetos ou comportamento de cuidado para com o outro (Almeida, 2008). Heidegger (2005, p. 258) afirma, "enquanto totalidade originária de sua estrutura, a cura se acha, do ponto de vista existencial - a priori, 'antes' de toda 'atitude' e 'situação' da pre-sença, o que sempre significa dizer que ela se acha em toda atitude e situação de fato".

Para testemunhar a condição pré-ontológica do Cuidado, Heidegger (2005) recorre à Fábula de Higino. Por meio desta fábula apresentada em Ser e Tempo, entende-se que a existência do ser do Dasein é constituída pelo Cuidado. Cuidado (Sorge) é o que há de mais originário na existência do Dasein, de modo que a ocupação (Bersorge) com as coisas e a preocupação (Fürsorge) com os demais advêm dele (Kahlmeyer-Mertens, 2015). O humano é dado ao Cuidado durante toda sua existência, em toda ação. Como ser-no-mundo, sempre pertencerá ao Cuidado (Fernandes, 2011).

O entendimento do ser do homem como existência conduzida pelo Cuidado leva a concepções e atitudes diferenciadas no campo da saúde, como: o rompimento com concepções objetivantes do sofrimento existencial, que reduzem o humano a dimensões orgânicas, psicológicas ou sociais; o afastamento de atitude tecnicista, em que o profissional se posiciona como condutor do processo, segundo suas bases teórico-conceituais sobre a existência da pessoa assistida ou conforme sua vontade pessoal de curá-lo; e a prática de uma atenção e escuta desprendida de qualquer expectativa, na qual o outro é chamado a uma lembrança de si como existência, para, então, alcançar os limites e as possibilidades mais singulares (Sá e Barreto, 2011).

Fukumitsu et al. (2009), também com base em uma compreensão fenomenológica, discorrem sobre o exercício do cuidado no interior dos dispositivos de saúde. Os autores explicam que o cuidar acontece em uma dinâmica entre duas pessoas - o profissional e a pessoa que foi em busca dos dispositivos de saúde - e a partir dela se abrem possibilidades para que o potencial de saúde venha a emergir neste contexto. O profissional de saúde que se volta para outro ser humano é visto, pelos autores, como um cuidador, não no sentido de fazer 'por', mas de fazer 'com' o outro. Esta pequena diferença, segundo 
os autores, apresenta concordância com o pensamento existencial, em que ser-com possui um significado ontológico do caráter relacional e como elemento constitutivo da existência humana. Quando se faz 'por', a ênfase está nos atos, de ajudar ou de atender às necessidades, e não há, necessariamente, um compromisso com a relação.

Valorizar a relação implica possibilitar que o cuidado apareça, ao criar condições fundamentais para que isto ocorra. O cuidado é construído quando a existência da pessoa assistida adquire significado para aqueles que estão envolvidos na assistência. Deste modo, o profissional apresenta disponibilidade para participar das escolhas, dos sofrimentos, desejos e conquistas da pessoa, assim como esta apresenta disponibilidade para compartilhar sua vida. Cuidado implica "compreender o outro como um ser humano em busca de conhecimento de seus processos, que muitas vezes transcendem o próprio sintoma que ele expressa" (Fukumitsu et al. 2009, p. 173). O cuidado pode ser compreendido como uma condição existencial e, também, como um processo que se encontra nas relações estabelecidas entre os profissionais de saúde e as pessoas que os procuram, com vistas a amenizar o sofrimento. Neste sentido, é enfatizado o 'fazer com', ao se levar em consideração o contexto em que ambos se encontram, uma vez que o cuidado implica disponibilidades (Fukumitsu et al., 2009).

Utilizando-se, também, do arsenal fenomenológico heideggeriano, Ayres (2009, p. 27) apresenta a concepção de cuidado intersubjetivo e elenca aspectos fundamentais para a compreensão dele. São eles: subjetividade não corresponde à mesmice, é, na verdade, intersubjetividade, pois é sempre relação; esta relação possui um sentido existencial, é configurada como "encontro desejante com a circunstância", ou seja, é colocar-se diante do outro e construir copossibilidades em um mundo compartilhado; e o que movimenta este encontro desejante entre os sujeitos e seu mundo não remete apenas ao êxito técnico, mas a uma situação que engloba felicidade, dimensões éticas e estéticas, refere-se a um sucesso. Com este entendimento, o autor ressalta que é preciso assumir que o importante na atenção à saúde é a intersubjetividade experienciada por meio de suas práticas.

Ayres (2009) apresenta uma importante reflexão acerca das tecnologias de assistência à saúde, como e pelo que têm sido conduzidas, por vezes, comprometendo o encontro terapêutico. O autor identifica que o fundamento dos discursos normativos e corretivos das ações de saúde é a utópica relação entre conhecimento e controle de agravos e doenças. A atitude fenomenológica diante das práticas de saúde não visa a eliminar as ações terapêuticas convencionais, mas a retirar a centralidade que ocupam na atenção à saúde, 'subordinando-as' “a uma atenção que busca sustentar a lembrança da dinâmica de realização da relação terapêutica enquanto possibilidade ôntica da nossa condição ontológica de ser-no-mundo-com-o-outro"' (Sá e Barreto, 2011, p. 393). 
Ayres (2009) afirma que a constituição de intersubjetividade acontece sempre acompanhada da atuação de um sucesso prático. Com isso, destaca a importância de os profissionais, aqueles que estão dispostos a cuidar, buscarem conhecer a concepção de vida que conduz os projetos existenciais das pessoas a quem prestam assistência, os chamados projetos de felicidade. Este pode ser entendido como "totalidade compreensiva que dá sentido existencial às demandas postas aos profissionais e serviços de saúde pelos destinatários de suas ações" (Ayres, 2009, p. 140).

Com base neste arsenal teórico, busquei, com esta pesquisa, os sentidos do cuidado em saúde mental presentes nos dispositivos da RAPS do SUS.

\section{Percurso metodológico}

Este artigo apresenta parte dos resultados da dissertação intitulada Sentido do Cuidado em Saúde Mental na Rede de Atenção Psicossocial do SUS. A pesquisa foi construída com base na compreensão hermenêutica heideggeriana.

Heidegger inaugura um novo campo de investigação para a filosofia, assentado em um retorno à vida e às experiências que dela emergem, “a filosofia volta a aventurar-se no perigoso e incontrolável acontecer da vida, fora do âmbito da certeza, segurança e objetividade" (Seibt, 2012, p. 86). O olhar hermenêutico de Heidegger aponta para o entendimento de que, antes de qualquer coisa, o homem está facticamente situado no mundo, é ser-nomundo e que, por meio disso, se dão as teorizações. Deste modo, entende-se que não existe separação entre sujeito e objeto. A vivência não está diante do indivíduo como objeto, ao contrário, ele está envolvido nela, faz parte do seu fluxo. A proposta de Heidegger prioriza o acompanhamento da vivência que não está colocada a partir do de fora, "mas constitui a si mesmo nesse fluxo compreensivo-interpretativo da vivência" (Seibt, 2012, p. 93).

Na construção deste estudo busquei, como inspiração e referência, os moldes do fazer etnográfico. A etnografia é uma prática de pesquisa nascida no campo da Antropologia. Esta prática ultrapassa a noção de uma simples questão de método, pois não é definida por técnicas e procedimentos determinados, mas, sim, pelo "esforço intelectual" que representa o lançar-se arriscado de seus praticantes em direção à descrição densa (Geertz, 2008, p. 4).

$\mathrm{O}$ esforço empreendido nesta pesquisa na captura do cuidado ocorreu com a seleção de 21 imagens fotográficas que retratam distintas vivências ocorridas no interior de diferentes dispositivos de saúde mental do SUS do Brasil. O contato com as imagens e as considerações que daí partiram decorreram da relação estabelecida entre mim e as imagens fotográficas. Apoiada nelas, lancei-me a reflexões acerca dos perfis de cuidado e suas complexas relações no contexto da saúde mental. 
A relação entre as ciências sociais e a imagem vem de longa data e se faz permeada por diferentes momentos de afastamentos e resistências, ainda que em seu início tenha parecido promissora. Por longo período predominou, como empecilho, a concepção de suposta neutralidade, objetividade e transparência para a utilização de recursos audiovisuais. Posteriormente, influenciados pelos pensamentos pós-positivista e pós-moderno, passou-se a entender que as fotografias e filmes retratam o que está diante deles, um contexto sociocultural, assim como expressam o olhar daqueles que as produziram (Campos, 2011). Acrescenta-se, também, a influência daquele que se propõe a analisá-las.

A maioria das imagens selecionadas neste estudo é proveniente de fontes de caráter jornalístico. Em virtude desta característica, recorri a Barthes (1982) para me orientar na relação com as imagens. De acordo com o autor, além da proposta de uma análise imanente, não se pode deixar de considerar que a estrutura da fotografia de imprensa não é isolada, sua comunicação se dá também com outra estrutura, que é o texto representado por título, legenda ou artigo, dos quais as fotografias estão sempre acompanhadas. Assim, a totalidade da informação se dá por meio de duas estruturas que são convergentes, porém não se misturam, pois cada uma ocupa seu espaço e tem sua função: a estrutura da linguística, constituída pelas palavras, e a estrutura fotográfica, composta por linhas, tonalidades etc. E, mesmo que toda fotografia de imprensa seja acompanhada por comentários escritos, Barthes (1982) recomenda que a análise aconteça primeiramente de cada estrutura, em separado.

Para o alcance do objetivo principal da pesquisa, o foco na estrutura fotográfica foi considerado suficiente. Optei por não decidir previamente se acessava as reportagens às quais as imagens estavam vinculadas, mas deixar que esta necessidade fosse evidenciada (ou não) nos momentos de encontro com cada fotografia.

O campo de coleta de dados deste estudo foi o espaço da internet, de onde foram pesquisadas imagens que me permitiram visualizar e refletir sobre o cuidado intersubjetivo expresso nas vivências das pessoas em sofrimento psíquico no interior dos dispositivos de saúde mental na atualidade. De acordo com Kozinets (2014), uma das interfaces do estudo on-line é a oportunidade de pesquisar um fenômeno social cuja existência extrapola os limites da internet, ou seja, que está presente no espaço on-line, mas que é articulado com os demais ambientes fora dele. Este desafio metodológico foi proposto com base no do entendimento de que o conteúdo encontrado na internet está intrinsecamente relacionado com as práticas executadas no contexto externo, digo, com o que acontece no âmbito offline. Conforme atestam Rocha e Montardo (2005, p. 10), existe "um mundo que também se desenrola no ciberespaço e que tende a cada dia diminuir concretamente a fronteira entre real e virtual". Deste modo, foi realizada uma pesquisa etnográfica aplicada à internet. 
Realizei as buscas pelas imagens fotográficas no site de busca Google Search Imagens. Para localizar as fotografias, utilizei diferentes expressões, de acordo com o interesse do estudo. Nos registros nos diários de campo, mencionei somente as consignas que resultaram em imagens para o estudo e descartei as que não trouxeram contribuições. As expressões usadas foram: "Centro de Atenção Psicossocial", "Hospital Psiquiátrico SUS", "Residências Terapêuticas", "Louco SUS", "Rede de Atenção Psicossocial", "Loucura CAPS" e "Consultório na Rua". As expressões foram usadas mais de uma vez, em diferentes momentos de busca.

As consignas resultaram em imagens de diferentes dispositivos, uma vez que, vale dizer, selecionei-as baseada em termos próprios também à RAPS. E ainda encontrei imagens de momentos de mobilizações coletivas em prol das causas do setor da saúde mental. No total, coletei 145 imagens fotográficas a serem selecionadas para o estudo. Para cada uma dessas imagens, capturei, por meio da tecla print screen, imagens da tela do computador que retratam as reportagens ou contextos dos quais provêm as imagens fotográficas. Deste modo, em 16 visitas de campo on-line, coletei 246 imagens, num período de quatro meses (de junho a outubro de 2015).

Registrei os momentos de coleta das imagens no ambiente on-line em um diário de campo. As anotações aconteceram de forma concomitante ao seguimento das buscas, a fim de registrar detalhes e peculiaridades de cada momento da pesquisa. Deste modo, o diário de campo foi organizado na sequência de visitas realizadas no campo on-line. Nele, armazenei os links por meio dos quais as imagens e as respectivas legendas podem ser encontradas. Além disso, relatei as especificidades de cada situação de busca que, por vezes, fomentaram pensamentos, impressões e reflexões próprios da imagem coletada ou do contexto em que se encontrava. Também registrei os impactos do contato com as imagens, as experiências no campo on-line, as descobertas e reflexões sobre questões concernentes ao cuidado na RAPS.

Para a análise, optei por abordar somente as imagens que retratam acontecimentos nos Centros de Atenção Psicossocial (CAPS), nas Residências Terapêuticas (RT) e nos Hospitais Psiquiátricos (HP). A escolha por estes dispositivos foi realizada com base nos momentos de coleta, em que as imagens me afetaram mais profundamente. Assim, selecionei cinco imagens referentes aos CAPS, oito imagens referentes aos Hospitais Psiquiátricos e também oito imagens atreladas às Residências Terapêuticas.

No primeiro momento analítico, para cada uma das imagens selecionadas, realizei anotações minuciosas acerca da cena retratada e dos significados que emergiram mediante observação atenta e reflexão sobre os aspectos presentes na imagem que corresponde ao cotidiano dos dispositivos da RAPS. Organizei as situações relatadas em temas emergentes, de acordo com dispositivos correspondentes. Com este exercício, registrei associações que contribuíram 
para o alcance dos significados presentes nas imagens e, posteriormente, para a discussão acerca do cuidado no âmbito da saúde mental.

\section{Dinâmica dos Centros de Atenção Psicossocial}

Uma das fotografias retratou a ocasião de uma apresentação musical dos usuários, em que cada um tinha em mãos um instrumento. Imagino que esta atividade tenha sido resultado de uma oficina terapêutica com o objetivo de explorar diferentes tipos de sons, produzir instrumentos e outras interações musicais (Prefeitura de João Pessoa, 2015). Outra imagem me parece também remeter à oficina terapêutica, pois apresenta usuários segurando objetos que parecem ter sido confeccionados por eles próprios, visto que cada um dispõe de um objeto com características diferenciadas (Prefeitura de Santo Amaro, 2014). Parece tratar-se de uma oficina voltada para artesanato. Essas imagens sugerem a demonstração de resultados de atividades desenvolvidas em oficinas terapêuticas oferecidas pelos CAPS aos usuários.

Observei também a ocorrência de festas temáticas realizadas neste dispositivo. As imagens retratam usuários fantasiados e com pinturas no rosto. Com base nas caracterizações, entendo que se tratavam de festas de carnaval. A imagem de um casal fantasiado de rei e rainha do carnaval sugere a realização de um concurso entre os usuários (180 graus, 2014).

Mediante a observação dessas imagens, pode-se refletir acerca da funcionalidade dessas atividades no contexto do CAPS e, também, sobre a importância que adquirem na vida dos usuários que frequentam o dispositivo. Guljor (2003) enfatiza que a atenção psicossocial se diferencia do modelo hospitalocêntrico no modo como são desenvolvidas as ações. Nos dispositivos psicossociais, a prioridade é dada para atividades coletivas, que estimulam os usuários a interagirem, capacitando-os para o desenvolvimento de relações em outros espaços de convívio.

As oficinas terapêuticas e as confraternizações retratadas nas imagens parecem contribuir para maior convivência entre os usuários. Porém, é preciso atentar para o sentido dado a estas programações. Estas atividades podem proporcionar momentos de interação, de relação com todas as pessoas envolvidas, e serem resultado de uma construção conjunta entre equipe de saúde mental e usuários que fazem parte do dispositivo. Ou, em contraposição, podem ser reduzidas apenas a ações estabelecidas no calendário institucional, como um conjunto de procedimentos e operações elaboradas por parte da equipe, fundamentadas no que imaginam que os usuários gostariam, sem envolvimento e interação alguma com eles.

Em outra fotografia a cena me chamou atenção para o exercício de uma atividade voltada para o aspecto físico: parece se tratar de fisioterapia (Unipê, 2010). Esta imagem levou à reflexão acerca da importância do desenvolvimento, 
no interior dos CAPS, de atividades corporais que, por vezes, neste contexto, podem ser esquecidas ou qualificadas como de menor importância. Além deste aspecto, a imagem mostra a interação da profissional de saúde com a usuária durante o exercício proposto.

$\mathrm{Na}$ fotografia, a profissional encontra-se próxima à usuária, com o rosto voltado para ela. A profissional segura o braço da usuária com uma das mãos e, com a outra, a toca nas costas. Pela posição em que elas se encontram, a profissional parece estar auxiliando a usuária. Por esta imagem, pode-se constatar que qualquer prática de saúde pode proporcionar uma troca intersubjetiva em que a pessoa atendida seja considerada em suas diferentes dimensões e incluída na construção daquele momento.

\section{Ambiente do CAPS}

As imagens referentes aos CAPS também me possibilitaram conhecer um pouco sobre o ambiente desses dispositivos e identificar aspectos comuns das unidades retratadas. Duas fotografias mostram o ambiente decorado com desenhos festivos, cartazes confeccionados com tinta, figuras, desenhos e diferentes textos, enfeites produzidos artesanalmente, como telas de pintura e outros objetos que parecem ser resultados de oficinas terapêuticas. Em uma das imagens, a parede é cor de rosa. Desta forma, os ambientes dos CAPS mostraram-se bastante coloridos e com diferentes enfeites. Outro fator que chamou atenção foi a utilização de objetos que parecem infantis. Uma das imagens mostra, na atividade musical, dois usuários com pandeiros de tamanho menor que o padrão e nas cores azul e amarelo (Prefeitura de Santo Amaro, 2014; Prefeitura de João Pessoa, 2015).

Esta combinação de ambientes coloridos, enfeitados, e objetos que pareceram brinquedos me reportam a outro espaço: o de educação infantil. Com isso, tornou-se fundamental refletir sobre as práticas no interior dos CAPS. Este modo de decorar o ambiente teria sido requisitado pelos usuários que lá frequentam ou advém da equipe de saúde por entender ser este o ambiente adequado para os usuários? E, ainda, em decorrência disto, questiono se esta forma de arrumação, que se confunde com uma forma infantilizada, reflete a maneira como os usuários são tratados pelos profissionais, fundada em uma noção de tutela, de incapacidade, de fragilidade que remete a uma criança. Em contrapartida, em outro CAPS, me chamou atenção a parede branca, sem enfeites e/ou cartazes, que dava a impressão de ser uma casa, uma residência familiar, com estante de livros, sofá, porta-revistas.

A questão trazida por Ayres (2009), quando fala de saúde, sobre considerar o que as pessoas pensam e desejam a respeito de si mesmas, recai também sobre o modo de arrumação do ambiente. Como destacou Guljor (2003), é im- 
portante considerar a relação dos usuários não somente com os profissionais, mas também com o espaço, pois este passa a ser referência para pessoas que utilizam os dispositivos psicossociais.

\section{Paradigma biomédico no interior do CAPS}

Uma das fotografias retratou a presença de um profissional vestido com jaleco em um ambiente do CAPS, na execução de uma atividade aparentemente de baixa ou nenhuma insalubridade (Unipê, 2010). Esta foto me instigou acerca da presença do paradigma biomédico no interior do CAPS. Pois sinaliza para uma ameaça à concretização de um dos maiores anseios da Reforma Psiquiátrica Brasileira: o CAPS como dispositivo estratégico para o rompimento com o paradigma da loucura e aproximação do convívio social de forma a estimular a transformação social, conforme apontado em Brasil (2004).

$\mathrm{O}$ uso do jaleco, naquele contexto, pode estar fundamentado em uma visão de cuidado pautada nos procedimentos técnicos ou, como aponta Merhy (2002), nas chamadas tecnologias duras e leve-duras. Ou ainda, como enfatiza Ayres (2009), numa preocupação com o êxito técnico. Ambas as concepções denotam uma valorização do conhecimento e da técnica a ser aplicada ou desenvolvida e na subvalorização do contexto e da pessoa.

O cuidado operacional em saúde guarda relações com o modelo biomédico, em que o saber científico conduz, determina e normatiza as práticas. Esta postura não tem a ver com o tipo de cuidado que visa a intersubjetividade, que possui entre as principais premissas o afastamento do paradigma que centra as ações na doença e que adota uma atitude de poder perante a pessoa assistida.

Essas noções de poder, controle, tratamento, técnicas a serem aplicadas têm maior probabilidade de desenvolver relações estáticas, individualizantes e objetificadoras entre profissionais e usuários, transformando-os em alvos de intervenções. "Estamos falando de um norte prático, necessariamente técnico, mas também inexoravelmente ético, afetivo, estético" (Ayres, 2009, p. 35). Deste modo, cuidar, ainda que passe pelas competências técnicas, não se prende a tais noções.

\section{Condições presentes no cotidiano de hospitais psiquiátricos}

Por meio das imagens, observei condições estruturais dos hospitais psiquiátricos, que remetem à falta de manutenção e reparos. Identifiquei situações em que os internos conviviam em ambientes que necessitavam de limpeza, com colchões rasgados, poças de água, buracos no chão do dormitório, camas de tamanho menor que o necessário, falta de travesseiros. As situações 
retratadas nas imagens apresentam a estrutura precária ainda presente nas instituições psiquiátricas, com condições extremamente desagradáveis.

Em uma foto, a pintura das paredes já desgastada, o banco de concreto que não é possível movimentar e o mato que cresce desordenadamente me remeteram a uma ausência de novidade. As pessoas presentes na cena mostram-se inertes quanto à instituição e ao funcionamento dela, parecem acostumadas com o 'estar ali' sem nenhuma atividade específica (Branco, 2015; Crispim, 2015; Frente Nacional contra a Privatização da Saúde, 2013; Lins, 2015). A imagem me trouxe a impressão de um cotidiano que acontece sem expectativas.

Outra imagem me remete a uma apatia quanto à própria instituição, as árvores secas, as pessoas sem muita direção ou razão de estarem ali, a cor da estrutura já envelhecida (Silva, 2015). Todos os elementos mostraram uma instituição sem vida, sem movimento, talvez perdida quanto à sua funcionalidade e relevância, repetindo ações e protocolos por anos, sem reconhecer ao certo sua função ou sua importância. Perdida quanto ao seu sentido.

Com estes aspectos presentes nas imagens, atenta-se para a permanência, ainda, de algumas pautas de reivindicações realizadas no advento da Reforma Psiquiátrica Brasileira. Conforme foi visto, os profissionais de saúde mental, no final da década de 1970 e no decorrer dos anos 1980, protestavam contra situações presentes em hospitais psiquiátricos consideradas indignas do ser humano. Ainda que, em proporções diferentes, nota-se que as mudanças estruturais aclamadas pelos reformistas não se deram completamente. Podem ser vistas, ainda hoje, por meio das fotografias, condições desfavoráveis e precárias no interior dos hospitais psiquiátricos.

O cotidiano vazio e a apatia que foram percebidos nos hospitais psiquiátricos podem demonstrar que o modo de assistir e cuidar das pessoas em sofrimento mental, dentro dos hospitais, ainda não foi totalmente transformado. Eles podem também revelar uma lacuna deixada pela Reforma Psiquiátrica Brasileira quanto ao alcance destas transformações para o hospital, uma vez que o foco parece ter sido direcionado mais fortemente para os dispositivos substitutivos. Parece que o hospital não sofreu alterações, que o âmbito hospitalar foi esquecido no que se refere às mudanças e alterações pretendidas pela reforma. Deste modo, resquícios da lógica manicomial ainda podem ser identificados.

Relaciono, ainda, o cotidiano vazio e a apatia na prática hospitalar à noção de cuidado em saúde atrelada ao conjunto de ações específicas direcionadas a um problema, com a finalidade única de prover resolutividade, e ao paradigma racionalista problema-solução descrito por Rotelli et al. (1990). Como mencionado por estes autores, a busca pela cura torna incoerentes as ações em Psiquiatria, visto que a cronicidade tem sido uma das principais características do sofrimento psíquico considerado persistente e grave. Com base nisto, pensa-se que o cotidiano estático, percebido nos hospitais psiquiátricos, 
advém de uma prática relacionada a esta noção de cuidado em saúde, que é presa às ações que não alcançam resolutividade tendencialmente ótima, como é esperado. Pode-se dizer que o hospital psiquiátrico se perde quanto à sua funcionalidade, quando se restringe somente a aplicar técnicas destinadas à remissão de sintomas e constrói, deste modo, cotidianos vazios.

\section{Indícios de Cuidado na prática de saúde em hospitais psiquiátricos}

Uma imagem referente ao Hospital Psiquiátrico retrata um momento assistencial e remete a indícios de valorização da pessoa assistida. Certamente, por meio de uma imagem se torna difícil caracterizar o momento vivido e o que de fato aconteceu. Esta imagem, porém, permite conjeturar, por meio das posições em que as pessoas se encontram: o rosto da profissional virado para a usuária; o abraço que se faz enquanto caminham pelo corredor e, também, o braço do outro profissional, estendido ao ombro da usuária, enquanto percorrem o trajeto (Dantas, 2012).

Esses elementos me fazem pensar que o momento retratado pode não ter sido direcionado somente pelos procedimentos que devem ter sido adotados, mas por um significado dado à vida e experiência da usuária. Na verdade, remete a uma experiência de todos os envolvidos, dos profissionais no acompanhamento da usuária e da usuária sendo acompanhada por eles.

Como foi pontuado por Ayres (2009), a identidade subjetiva se faz na experiência com o outro, no encontro. Fukumitsu et al. (2009) também pontuam que o cuidado se dá nas relações estabelecidas entre os profissionais e usuários que, a partir daí, buscam a redução do sofrimento. Os autores enfatizam, neste processo de cuidado, o 'fazer com', que significa o encontro dos envolvidos e a disponibilidade de ambos na construção do momento assistencial.

Em outra fotografia foi possível notar a arrumação das camas presentes na imagem, uma diferente da outra (Gonçalves, 2015). O que remete à possibilidade de as pessoas internadas arrumarem suas camas. As cobertas, diferentes umas das outras, também indicam a possibilidade de que tenham seus objetos pessoais. Todavia, apesar de apontar para certa particularidade, isto ainda é considerado muito pouco para que se ateste, de fato, como um aspecto positivo quanto à liberdade ou autonomia dentro da instituição.

\section{O paradigma psiquiátrico na Residência Terapêutica}

Foram selecionadas oito imagens referentes às Residências Terapêuticas. Uma entre elas me pareceu sinalizar o modo como a lógica psiquiátrica pode ser 
inserida e se fazer presente neste espaço, ainda que seja um dispositivo substitutivo, elaborado com base no paradigma da atenção psicossocial.

Nessa imagem, foi retratado um momento em que estavam moradores de uma residência terapêutica e um grupo de estudantes e/ou profissionais de saúde em um ambiente aberto, que parece uma praça. As pessoas estão posicionadas para a foto e um rapaz, identificado como um dos estudantes/ profissionais, segura um violão em uma das mãos. Os estudantes/profissionais são reconhecidos pelo uso de jaleco branco (Jornal Tabloide, 2015). Nesta imagem, os moradores não me parecem interessados em compor a foto. $\mathrm{Al}$ guns apresentam expressões e posições que conotam insatisfação, enquanto os estudantes/profissionais mostram-se sorridentes.

O evento registrado pareceu uma ação despreocupada quanto ao real interesse e querer dos moradores em participar daquele momento. Imagino que a atividade foi proposta pela equipe de saúde, considerando que esta seria uma boa ação a ser oferecida aos moradores. Porém, imagino também que a demanda não tenha emergido de um momento de encontro intersubjetivo construído pelos estudantes/profissionais e, igualmente, pelos moradores da Residência Terapêutica. Esta atitude parece corroborar a posição defendida por Leal e Munõz (2014) segundo a qual, para possibilitar a convivência de pessoas em sofrimento psíquico em sociedade, é necessária a aplicação de procedimentos adequados que estimulem o controle dos sintomas e o cuidado com a doença, fora do ambiente hospitalar.

Ayres (2009) alerta que a prática profissional em saúde não pode ser limitada a aspectos tecnológicos, pois, segundo o autor, a arte de assistir não pode ser restrita à mera manipulação de objetos. E pontua: ninguém pode tirar de uma pessoa, acerca do seu bem-estar, a decisão quanto às suas necessidades. Quando os profissionais deixam de perguntar sobre o que as pessoas sonham para sua saúde e para o seu bem-viver, a tendência será sempre uma atuação pautada na negatividade da doença e limitada aos conhecimentos para obtenção do controle e, deste modo, as práticas de saúde perdem pouco a pouco a sensibilidade diante das necessidades das pessoas (Ayres, 2009).

\section{Ações cotidianas das Residências Terapêuticas}

Foram identificados aspectos do cotidiano das Residências Terapêuticas. Percebi que, em quatro das oito imagens selecionadas, aparece um aparelho de televisão. Duas delas retratam o momento em que os moradores assistem à tevê. Desta forma, a presença do televisor ganhou destaque na análise das imagens e foi reconhecido como utensílio doméstico que ganha centralidade nas residências. Foram encontradas também outras imagens que retratam momentos do dia a dia nas residências, como a dos moradores fazendo uso 
da cozinha; na sala, assistindo à televisão; ou conversando entre eles, em diferentes cômodos da casa (Rocha, 2006).

Com isso, pode-se considerar o aspecto da convivência cotidiana dos moradores que, em prol de uma atividade comum, como assistir televisão ou compartilhar quarto, dentre outras possíveis, podem desenvolver interações, amizades, trocas de experiências. Enfim, podem ser promovidas interações cuidadosas e, do interior da casa, a ressocialização ser estimulada.

Outro aspecto muito importante identificado foi o sentimento de pertencimento dos moradores em relação à casa, ao endereço, ao bairro em que moram. Em uma cena retratada, o morador faz um sinal de cumprimento que parece um 'até logo'. Ele está sentado do lado de dentro da casa, próximo à janela (Souza, 2011). Esta imagem me trouxe a impressão de familiaridade, da relação de moradia estabelecida com a residência. O tipo de convivência proporcionada nas Residências Terapêuticas se torna importante porque à medida que os moradores se relacionam uns com outros, com a casa, com os utensílios e com as diferentes situações advindas do dia a dia, eles identificam a si mesmos e se reconhecem como pessoas (Ayres, 2009).

\section{Discussão}

No decorrer deste estudo, procurou-se demarcar a diferença teórico-conceitual entre o que se pode chamar cuidado operacionalizado (baseado em ações, assimetria, procedimentos e tratamentos) e cuidado intersubjetivo na prática em saúde mental. Com base no referencial teórico apresentado, foi possível elencar os modos como cada concepção de cuidado se apresenta no exercício das ações em saúde.

As imagens dos dispositivos da RAPS e as reflexões suscitadas por meio delas apontaram para a prevalência da presença do cuidado do tipo operacionalizado, voltado para os procedimentos e para o que preconizam as cartilhas institucionais acerca destes dispositivos, priorizando o funcionamento estrutural destes espaços e, consequentemente, produzindo certo apagamento das pessoas que lá se encontram.

O cuidado intersubjetivo não apareceu nas imagens, não foi retratado. Sabe-se que o cuidado pautado na intersubjetividade é um fenômeno que emerge na relação entre as pessoas envolvidas no momento assistencial, não é algo palpável, assim como também não se reduz a aspectos objetiváveis e observáveis, mas se dá na experiência. É na relação que pode ser identificado o sentido dado pelas pessoas envolvidas, no que sentem durante e após o encontro assistencial. Contudo, na relação que estabeleci com as imagens e, deste modo, também contemplando a cena, o cuidado intersubjetivo não emergiu. 
Mas, ainda que não tenha sido retratado o cuidado intersubjetivo, diferentes imagens sinalizaram momentos em que existiam possibilidades para que este perfil de cuidado emergisse. A partir daí, aponto para o fato de que em todo momento assistencial em saúde mental, independentemente do dispositivo, existe abertura para a valorização da relação, para a troca intersubjetiva entre o profissional e o usuário. Seja por meio de uma atividade terapêutica no interior do CAPS, seja por meio de uma visita a uma residência terapêutica ou de uma recepção no hospital psiquiátrico. Em qualquer ação, a pessoa assistida pode ser valorizada.

\section{Considerações finais}

Ainda que a proposta dos dispositivos substitutivos seja romper com as concepções tradicionais da psiquiatria, existe a necessidade de avanços para o alcance pleno deste ideal. As imagens retrataram mudanças significativas quanto ao modo de assistir a pessoa em sofrimento psíquico no Brasil, que para seguir avançando, precisa cada vez mais - e sempre - desconstruir o paradigma psiquiátrico em torno da loucura e a noção de cuidado pautado em técnicas definidas e efetivas, desconstruir a noção de periculosidade e afastamento das pessoas em sofrimento psíquico considerado grave, dentre outros tantos desafios.

O cuidado considerado necessário para o âmbito da saúde mental e que, certamente, contribui para a progressão da Reforma Psiquiátrica Brasileira é o que valoriza as pessoas, reconhece seus contextos de vida, se interessa por seus sentimentos e mantém expectativas quanto ao que os profissionais podem vir a colaborar para a satisfação das suas necessidades, para a redução do seu sofrimento e para a reconfiguração dos dispositivos de saúde. É este o cuidado que considera os diferentes modos de ser, sem querer padronizar, normatizar. É um perfil de cuidado que dá abertura para que o usuário se encontre em suas possibilidades de ser e utilize os recursos necessários para isso, uma vez que, este mesmo usuário, por ser Dasein, é Cuidado.

\section{Agradecimentos}

À Fundação para o Desenvolvimento Científico e Tecnológico em Saúde (Fiotec), pelo financiamento desta pesquisa. 
Resumen Diferentes concepciones de cuidado permean el sector de la salud y influencian las prácticas adoptadas en todos los campos, incluso el de la salud mental. En esta investigación se buscó sentido para el cuidado en salud mental en la Red de Atención Psicosocial del Sistema Único de Salud de Brasil. El estudio se configura metodológicamente como cualitativo de cuño fenomenológico, con base en el referencial hermenéutico de Heidegger. El camino analítico fue inspirado, también, por el referencial de la Antropología Visual y su hacer etnográfico. El esfuerzo empreendido ocurrió con la selección de 21 fotografías que retrata vivencias que apuntan al cuidado ejercido en el interior de los dispositivos de salud mental. Por medio de estas imágenes, el sentido del cuidado ejercido en los dispositivos de la Red de Atención Psicosocial del Sistema Único de Salud surgió como aún atado a la noción de cuidado basado en acciones efectivas y al funcionamiento considerado adecuado exclusivamente por medio del cumplimiento de protocolos, criterios y actividades asistenciales preconizadas en los manuales. El cuidado considerado necesario para el ámbito de la salud mental es lo que valora a la personas, se interesa por sus sentimientos y mantiene expectativas en cuanto a lo que los profesionales pueden venir a caloborar para la satisfacción de sus necesidades, para la reducción de su sufrimiento y para la reconfiguración de los dispositivos de salud.

Palabras clave salud mental; cuidado centrado em el paciente; sistema único de salud; etnografia; fotografia.

\section{Notas}

${ }^{1}$ Fundação Oswaldo Cruz, Escola Politécnica de Saúde Joaquim Venâncio, Rio de Janeiro, Brasil.

<arielly.psi@gmail.com>

Correspondência: Rua Job Bispo de Castro, 395, Real Parque, CEP 88113-330, São José, Santa Catarina, Brasil.

${ }^{2}$ Dasein, ser-aí, pre-sença, serão utilizados como sinônimos ao longo do texto, respeitando-se a forma como foram escritos originariamente nos textos referenciados. 


\section{Referências}

ALMEIDA, Rogério S. O cuidado na primeira seção de Ser e Tempo. Existência e Arte: Revista Eletrônica do Grupo PET, São João Del-Rei, v. 4, n. 4, jan.-dez., 2008. Disponível em: $<$ http://www.ufsj.edu.br/portal-repositorio/File/existenciaearte/Edicoes/4_Edicao/ rogerio_almeida.pdf>. Acesso em: $11 \mathrm{dez} .2015$.

AMARANTE, Paulo. A trajetória da reforma psiquiátrica no Brasil. In: AMARANTE, Paulo (org.). Loucos pela vida: a trajetória da reforma psiquiátrica no Brasil. 2. ed. Rio de Janeiro: Editora Fiocruz, 1995.

ARAÚJO, Nunes. Pacientes de Centro de Atenção Psicossocial comemoram com folia. 180 Graus, Parnaíba, 28 fev. 2014. 1 fotografia [sem autoria declarada]. Disponível em: <http://180graus. com/parnaiba/pacientes-de-centro-de-atencaopsicossocial-comemoram-com-folia>. Acesso em: 19 jun. 2015.

AYRES, José R. C. M. Cuidado: trabalho e interação nas práticas de saúde. Rio de Janeiro: Cepesc/UERJ/IMS: Abrasco, 2009.

BARTHES, Roland. A mensagem fotográfica. In: LIMA, Luiz C. Teoria da cultura de massa. Rio de Janeiro: Paz e Terra, 1982.

BRASIL. Ministério da Saúde. Secretaria de Atenção à Saúde. Departamento de Ações Programáticas Estratégicas. Saúde Mental no SUS: os centros de atenção psicossocial. Brasília: Ministério da Saúde, 2004. Disponível em: $<$ http://www.ccs.saude.gov.br/saude_mental/ pdf/sm_sus.pdf>. Acesso em: 28 jul. 2015.

BRASIL. Ministério da Saúde. Secretaria de Atenção à Saúde. Departamento de Ações Programáticas Estratégicas. Coordenação Geral de Saúde Mental. Reforma psiquiátrica e politica de saúde mental no Brasil: Conferência Regional de Reforma dos Serviços de Saúde Mental - 15 anos depois de Caracas. Brasília: Opas, 2005. Disponível em: <http://bvsms.saude.gov.br/bvs/publicacoes/ Relatorio15_anos_Caracas.pdf $>$. Acesso em: 28 jul. 2015.
BRASIL. Conselho Nacional de Saúde. Portaria n. 3.088, de 23 de dezembro de 2011. Institui a Rede de Atenção Psicossocial para pessoas com sofrimento ou transtorno mental e com necessidades decorrentes do uso de crack, álcool e outras drogas, no âmbito do Sistema Único de Saúde (SUS). Disponível em: <http://bvsms.saude.gov.br/bvs/ saudelegis/gm/2011/prt3088_23_12_2011_rep. html>. Acesso em: 28 jul. 2015.

BRANCO, Daniel C. Antigos pacientes do manicômio de Paracambi voltam à vida normal. O Dia, Rio de Janeiro, 23 maio 2015. 1 fotografia [Daniel Castelo Branco/Agência O Dia]. Disponível em: <http://odia.ig.com.br/ noticia/mundoeciencia/2015-05-23/pacientesdo-hospital-paracambi-estao-recebendo-altae-voltando-a-sociedade.html $>$. Acesso em: 18 jun. 2015.

CAMPOS, Ricardo. Imagem e tecnologias visuais em pesquisa social: tendência e desafios. Análise Social, Lisboa, v. 46, n. 199, p. 237-259, 2011. Disponível em: <http:// analisesocial.ics.ul.pt/documentos/131783 1186G5cUQ8iz4Gt87CI9.pdf>. Acesso em: 03 set. 2015.

CRISPIM, Roberto. Hospital Psiquiátrico do Crato ameaça encerrar as atividades. Pé no chão, Várzea Alegre, 23. Fev. 2015. 1 fotografia. Disponível em: <http://penochaoinformativo. blogspot.com.br/2015/02/saude-hospitalpsiquiatrico-do-crato.html $>$. Acesso em: 24 jun. 2015.

DANTAS, Aldair. Falta atendimento psiquiátrico no RN. 9 dez. 2012. 1 fotografia. Disponível em: <http://wwwmarconepedroblogspotcombr.blogspot.com.br/2012/12/ falta-atendimento-psiquiatrico-no-rn.html>. Acesso em: 23 out. 2015.

FERNANDES, Marcos A. Do cuidado da fenomenologia à fenomenologia do cuidado. In: PEIXOTO, Adão J.; HOLANDA, Adriano F. (orgs). Fenomenologia do cuidado e do cuidar: perspectivas multidisciplinares. Curitiba: Juruá, 2011. 
FRENTE NACIONAL CONTRA A PRIVATIZAÇÃO DA SAÚDE. Hospitais psiquiátricos sofrem intervenção. 2 mar. 2013. 1 fotografia [sem autoria declarada]. Disponível em: $<$ http:// www.contraprivatizacao.com.br/2013/03/ hospitais-psiquiatricos-sofrem.html $>$. Acesso em: 24 jun. 2015.

FUKUMITSU, Karina O. et al. O cuidado na saúde e da doença: uma perspectiva gestáltica. Estudos e Pesquisas em Psicologia, Rio de Janeiro, v. 9, n. 1, p. 172-182, jan.-jun., 2009. Disponível em: <http://www.revispsi. uerj.br/v9nl/artigos/pdf/v9nlal4.pdf>. Acesso em: 10 out. 2015.

GEERTZ, Clifford. Uma descrição densa: por uma teoria interpretativa da cultura. In: GEERTZ, Clifford. A interpretação das culturas. 1. ed. Rio de Janeiro: LTC, 2008.

GONÇALVES, Paulo. Hospital fechará as portas para o SUS em novembro. Hoje mais - Andralina. 01 set. 2015. 1 fotografia [Paulo Gonçalves/ Folha da Região]. Disponível em: <http://www. hojemais.com.br/mobile/andradina/noticia/ geral/hospital-fechara-as-portas-para-o-susem-novembro>. Acesso em: 23 out. 2015.

GULJOR, Ana P. F. Os centros de atenção psicossocial: um estudo sobre a transformação do modelo assistencial em saúde mental. 2003.197f. Dissertação (Mestrado em Saúde Pública) - Escola Nacional de Saúde Pública Sérgio Arouca, Rio de Janeiro, 2003.

HEIDEGGER, Martin. Conferências e escritos filosóficos. Tradução e nota de Ernildo Stein. São Paulo: Nova Cultural, 1989.

HEIDEGGER, Martin. Ser e Tempo. 15. ed. Petrópolis: Vozes, 2005.

JORNAL TABLOIDE. Serviço de residências terapêuticas promove manhã musical aos moradores. Jornal Tabloide, Ourinhos, 27 mar. 2015. 1 fotografia [sem autoria declarada]. Disponível em: <http://www.jornaltabloide.com/2015/03/ servico-de-residencias-terapeuticas.html $>$. Acesso em: 22 jul. 2015.
KAHLMEYER-MERTENS, Roberto S. Sobre ser constitutivamente cuidado. In: KAHLMEYERMERTENS, Roberto S. 10 lições sobre Heidegger. Petrópolis: Vozes, 2015.

KOZINETS, Robert V. Netnografia: realizando pesquisa etnográfica online. Porto Alegre: Penso, 2014.

LEAL, Erotildes M.; MUÑOZ, Nuria M. Estratégias de intervenção em saúde mental. In: JORGE, Marco A. S. et al. (orgs.). Politicas e cuidado em saúde mental: contribuições para a prática profissional. Rio de Janeiro: Editora Fiocruz, 2014.

LINS, Marina N. Em crise, hospital psiquiátrico de Paracambi passa a ser administrado pela prefeitura. Extra, Rio de Janeiro, 9 fev. 2015. 1 fotografia. Disponível em: <http:// extra.globo.com/noticias/rio/em-crise-hospitalpsiquiatrico-de-paracambi-passa-ser-administrado-pela-prefeitura-15273226.html>. Acesso em: 23 out. 2015.

MARTINS, Mônica. Qualidade do cuidado em saúde. In: SOUSA, Paulo; MENDES, Walter (orgs.). Segurança do paciente: conhecendo os riscos nas organizações de saúde. Rio de Janeiro: EAD/ENSP, 2014.

MERHY, Emerson E. Saúde: a cartografia do trabalho vivo. São Paulo: Hucitec, 2002.

PREFEITURA DE JOÃO PESSOA. SMS dispõe de serviço de Residência Terapêutica para pessoas com transtornos mentais. 1 fotografia [sem autoria declarada]. 2015. Disponível em: <http://www.joaopessoa.pb.gov.br/smsdispoe-de-servico-de-residencia-terapeuticapara-pessoas-com-transtornos-mentais $/>$. Acesso em: 6 out. 2015.

PREFEITURA DE SANTO AMARO (BAHIA). Reforma na estrutura do CAPS auxilia no atendimento a pacientes. 19 fev. 2014. 1 fotografia [sem autoria declarada]. Disponível em: $<$ https://prefeituradesantoamaro.wordpress. com/2014/02/page/2/> . Acesso em: 12 out 2015. 
ROCHA, Paula J.; MONTARDO, Sandra P. Netnografia: incursões metodológicas na cibercultura. Ecompos, Brasília, v. 4, dez. 2005. Disponível em: <http://compos.org.br/seer/ index.php/e-compos/article/viewFile/55/55>. Acesso em: 15 out. 2014.

ROCHA, Silvio. Residências Terapêuticas oferecem conforto e atenção aos portadores de transtornos psíquicos. Instituto Marcelo Déda, 4 maio 2006. 1 fotografia. Disponível em: <http://www.institutomarcelodeda.com.br/residencias-terapeuticasoferecem-conforto-e-atencao-aos-portadores-detranstornos-psiquicos/>. Acesso em: 22 jul. 2015.

ROTELLI, Franco et al. Desinstitucionalização. São Paulo: Editora Hucitec, 1990.

SCHECHTMAN, Alfredo; ALVES, Domingos S. A organização da política de saúde mental. In: JORGE, Marco A. S. et al. (orgs.). Políticas e cuidado em saúde mental: contribuições para a prática profissional. Rio de Janeiro: Editora Fiocruz, 2014.

SEIBT, Cezar L. Heidegger: da fenomenologia 'reflexiva' à fenomenologia hermenêutica. Princípios: Revista de Filosofia, Natal, n. 31, v. 19, p. 79-98, jan.-mar., 2012. Disponível em: $<$ https://periodicos.ufrn.br/principios/article/ view/7494/5563 > . Acesso em: 20 nov. 2015.

SÁ, Roberto N.; BARRETO, Carmem L. B. T. A noção de existência e as práticas psicológicas clínicas. Estudos de Psicologia. Campinas, v. 3. n. 28, p. 389-394, jul.-set. 2011. Disponível em: <http://www.scielo.br/pdf/estpsi/v28n3/ allv28n3.pdf $>$. Acesso em: 10 out. 2015.
SILVA, Marcelo A. A ontologia fundamental: a analítica, o Dasein. Um projeto em ser e tempo - Heidegger. In: SEMINÁRIO DE PESQUISA EM CIÊNCIAS HUMANAS, 4., 2012, Londrina, p. 970-979. Anais eletrônicos... Disponível em: <http://www.uel. br/eventos/sepech/arqtxt/PDF/marceloasilva. pdf $>$. Acesso em: 20 nov. 2015.

SILVA, Aldo V. Contrato com Teixeira Lima é prorrogado. Jornal Cruzeiro do Sul, Sorocaba, 15 maio 2015. 1 fotografia [Aldo V. Silva/ arquivo JCS]. Disponível em: <http://www. jornalcruzeiro.com.br/materia/609950/contratocom-teixeira-lima-e-prorrogado >. Acesso em: 11 jul. 2015.

SOUZA, Michele. Do isolamento em alas ao acolhimento em lares. O caminho de casa. UOL. 6 fotografias [Michele Souza/JC imagem]. 2011. Disponível em: <http://www2. uol.com.br/JC/sites/ocaminhodecasa/vinculada2.html\#galeria/vinculada2 > . Acesso em: 21 jul. 2015.

STEIN, Ernildo. Seis estudos sobre Ser e Tempo. 2. ed. Petrópolis: Vozes, 1990.

UNIPÊ. Centro Universitário de João Pessoa. Atuação da Fisioterapia no Centro de Apoio Psicossocial (CAPS). Blog. João Pessoa, 21 out. 2010. 1 fotografia [Sem autoria declarada].

Recebido em 09/05/2017. Aprovado em 23/08/2017. 